OPEN ACCESS

Edited by:

C. L. Teng,

International Medical

University, Malaysia

Reviewed by:

Mainul Haque,

National Defence University of Malaysia, Malaysia

Esha DasGupta,

International Medical

University, Malaysia

*Correspondence:

Nyi Nyi Naing

syedhatim@unisza.edu.my

Specialty section

This article was submitted to

Public Health Education and

Promotion,

a section of the journal

Frontiers in Public Health

Received: 12 August 2020 Accepted: 07 June 2021 Published: 01 July 2021

Citation:

Goni MD, Naing NN, Hasan H, Wan-Arfah N, Deris ZZ, Arifin WN, Baaba AA, Adam BM and Arshad MR

(2021) Effectiveness of a Novel

Smartphone Health Education Intervention in Enhancing Knowledge,

Attitudes, and Practices for the

Prevention of Respiratory Tract Infections Among Private Hajj Pilgrims

From Malaysia.

Front. Public Health 9:594204.

doi: 10.3389/fpubh.2021.594204

\section{Effectiveness of a Novel Smartphone Health Education Intervention in Enhancing Knowledge, Attitudes, and Practices for the Prevention of Respiratory Tract Infections Among Private Hajj Pilgrims From Malaysia}

\author{
Mohammed Dauda Goni ${ }^{1,2}$, Nyi Nyi Naing ${ }^{3 *}$, Habsah Hasan ${ }^{1}$, Nadiah Wan-Arfah ${ }^{4}$, \\ Zakuan Zainy Deris ${ }^{1}$, Wan Nor Arifin ${ }^{5}$, Aisha Abubakar Baaba ${ }^{6}$, \\ Babagana Mohammed Adam ${ }^{7}$ and Muhammad Rafie Arshad $^{8}$
}

\begin{abstract}
1 Department of Microbiology and Parasitology, School of Medical Sciences, Universiti Sains Malaysia, George Town, Malaysia, ${ }^{2}$ Faculty of Veterinary Medicine, Universiti Malaysia Kelantan, City Campus, Kota Bharu, Malaysia, ${ }^{3}$ Faculty of Medicine, Medical Campus, Universiti Sultan Zainal Abidin, Kuala Terengganu, Malaysia, ${ }^{4}$ Faculty of Health Sciences, Universiti Sultan Zainal Abidin, Kuala Terengganu, Malaysia, ${ }^{5}$ Unit of Biostatistics and Research Methodology, School of Medical Sciences, Universiti Sains Malaysia Health Campus, Kubang Kerian, Malaysia, ${ }^{6}$ Centre for Language Studies and Generic Development, Universiti Malaysia Kelantan, Kota Baharu, Malaysia, ${ }^{7}$ African Institute of One Health Research \& Diagnostics (AlOHRD), Abuja, Nigeria, ${ }^{8}$ School of Computer Sciences, Universiti Sains Malaysia, George Town, Malaysia
\end{abstract}

This study was aimed to develop and evaluate the efficacy of a health education program for increasing knowledge, changing attitudes, and promoting prevention practices to reduce the incidence of RTIs among Malaysian Hajj pilgrims. A quasi-experimental study was done among 130 Hajj pilgrims attending Hajj orientation course organized by a private Hajj tour companies. Hajj pilgrims assigned to intervention group $(n=65)$ and control group $(n=65)$. Data were collected baseline and after return from Hajj using a validated questionnaire. Mixed design repeated measure ANOVA was used to analyse the effect of group, time, and group-time interaction on the dependent variables. There was a significant improvement in knowledge, attitude and practice scores in the intervention group compared to the control group. Based on the findings of the interaction of time and group, there was a significant statistical difference for post intervention for knowledge $(p=0.005)$, attitude $(p=0.041)$, and practice $(p=0.002)$. The newly-established health education intervention smartphone application was effective in improving KAP toward RTIs prevention among pilgrims.

Keywords: intervention, respiratory tract infection, knowledge, attitude and practice, Hajj pilgrims

\section{INTRODUCTION}

Hajj pilgrimage is one of the largest annual mass gatherings which usually takes in Saudi Arabia with over 2 million pilgrims characterized by a high prevalence of respiratory illness among pilgrims from Malaysia and other parts of the world (1-3). There is a continued rise in the prevalence of RTIs despite the preventive practices among the Hajj pilgrims $(4,5)$. The COVID-19 pandemic 
that resulted in over 3,424,380 deaths with over 165 million people infected worldwide as at 11th August 2020 based on the figures from the Johns Hopkins University (6). The rapid transmission of the COVID-19 infection all over the world, the surge in confirmed cases as well as the lack of valid treatment and prophylaxis options, posed a serious threat to Hajj and other mass gatherings.

The usual practical approach of the protective measures appears inadequate to reduce it the incidence during the pilgrimage (7-9). Complementary and synergistic adherence to the various preventive practice such as proper hand hygiene, social distancing, vaccination, the use of face mask and cough etiquette must be ensured to achieve optimum protection (10). In Malaysia, a government Hajj Fund (Tabung Haji) is saddled with the responsibility of managing the Malaysian pilgrims during Hajj. They are the regulators and service provider for Hajj and Umrah for the pilgrims including the private tour companies.

Recent studies indicated a remarkable increase in healthrelated smartphone apps among the million users globally (11). Apps seem to be a befitting means of delivering practical and effective health education interventions (12). Various studies have reviewed the findings of the effectiveness of health-related apps targeting behavioral change interventions, such as physical activity and prevention of infections during Hajj as well as to trace pilgrims health behavior and obtain infectious disease data (13-16).

The gaps in the knowledge, including bad attitudes and poor practices regarding infection prevention and control, have been reported among healthcare workers during Hajj $(17,18)$. Some studies found out that the importance of bridging knowledge gaps concerning infectious disease diagnosis, treatment, prevention, and control have some negative attitudes and connect with health behavior (19). Therefore, people engage in poor practices, all of which contribute to their increased risk of infection and negative impacts on the community (20). A proper and well-planned health education intervention and the applicability of the acquired knowledge can serve as a base for improving the challenges, constraints and limitations, therefore directing resources and strategies toward the appropriate responses for the development of better health care.

The traditional Hajj orientation courses conducted by the Hajj agencies in Malaysia as well as the use posters, flyers, tv programmes to enlightened the pilgrims appears to be inadequate as can be seen in the increase in the incidence of the RTIs among Hajj and Umrah pilgrims. However, the importance of health education intervention module has not been evaluated among Hajj pilgrims. Also, there is no any health education intervention module via smartphone application that target behavior modification and improving preventive practices that are directed and specific for Hajj pilgrims regarding RTIs in Malaysia. Therefore, the objective of this study was to determine the effectiveness of a novel smartphone health education intervention module in improving knowledge, attitude, and practices of Malaysian Hajj pilgrims for the prevention of RTIs.

\section{METHODS}

\section{Study Design and Location}

A quasi-experimental study was conducted among Hajj pilgrims attending Hajj orientation course organized by two major different private Hajj company in Kelantan, Malaysia. Private Hajj companies have relatively smaller number of pilgrims and therefore easy to manage and trace the study participants after returning from the pilgrimage. The study was conducted in Kelantan State, Malaysia. The sample in our research will represent $\sim 20 \%$ of the total Malaysian pilgrims. Kelantan state is predominantly a Muslims state with about $96.8 \%$ of its population being Muslims and belongs to the Malay ethnic group. The sampling method used was cluster sampling, which was done in two stages. The first stage was a purposive selection of Hajj and Umrah companies as clusters. Each of the two companies were randomly allocated to intervention and control group, respectively. The intervention group received the health education intervention and the control group received a Hajj guide on regular Hajj routines developed by Mohamed et al. (21). Baseline data were collected from January 2019 to April 2019 before departure to Hajj and post-intervention immediately after return from Hajj. Hajj pilgrims aged 18 years and above who were willing to participate were included in the study. Pilgrim who cannot read and write and non-smartphone users were excluded from the study. This trial was guided by the Consolidated Standards of Reporting Trials (CONSORT) statement (22). In this type of study, a control group with comparable characteristics and functioning to the experimental group was selected. Randomization was not applied in this study. Open label was applied as it was not possible to blind the respondents, private Hajj companies management and investigators.

\section{Sample Size Calculation}

The sample size for this study was calculated by applying the formula for estimating sample size in hypothesis testing by comparing two means as outlined by Lemeshow et al. (23) using sample size calculator by Arifin (24). This formula gave the required number $(n)$ for each group. The estimated difference of mean knowledge score between intervention and control groups was selected based on standard deviation and effect size. Standard deviation value was taken from the pilot study, and 0.80 was selected as the value for effect size. The standard deviation of the mean knowledge score $=38.24$ from the pilot study. The estimated relative difference of mean knowledge score between intervention and control groups $(\Delta)=30 \%$. The minimum sample size needed was 26 participants per group. An additional $20.0 \%$ was added after considering drop-out from the study which resulted in $26+(26 \times 0.2)=33$. However, cluster design was applied in the present study. To accommodate the design effect, the calculated sample size was multiplied by two for correction. Therefore, the sample size required in this study was $(33 \times 2)=66$ per group. The total required sample size was $(66 \times 2)=132$ pilgrims in both the intervention and control groups. 


\section{Data Collection}

Participants were recruited during the Hajj orientation course from the two different Hajj companies. A trained data enumerator collected data from Hajj pilgrims who were given written informed consent to participate in the research. The pilgrims were briefed about the purpose of the study by the enumerators in easy and unambiguous terms. A validated, pretested and self-administered questionnaire was administered at the beginning of the orientation course were given to the participants to fill (25). The questionnaire administered in this study validated, pretested and self-administered consisting of four sections. The sections A, B, C and D, covered sociodemographic variables, RTI related knowledge, attitude toward RTI prevention and practices related to RTI prevention. Section A: it consists of 23 statements which cover socio-demographic characteristics studied including age, gender, race and marital status, occupational status, level of education, how many times have you performed Hajj or Umrah in the last 5 years, vaccinations history, and presence of comorbidities and presence of RTI before departure to Hajj. Section B: It had 9 questions with "Yes" or "No" options includes questions on knowledge of RTIs based on etiology, transmission, risk groups, signs and symptoms, complications, the use of PPE and prevention practices. Section C includes questions on prevention attitudes regarding RTI based on the health belief model and had 11 questions. The responses were on a 5-point Likert scale with the options: strongly agree, agree, not sure, disagree and strongly disagree. Section D: consists of questions related to prevention practices toward RTIs and had statements on the preventive practices of pilgrims relating to RTIs prevention with "Always," "Occasional," and "Never" options. Results of the reliability test carried out showed Cronbach's coefficient alpha for knowledge, attitude and practice was $0.831,0.777$, and 0.729 respectively.

\section{Health Education Intervention}

Hajj pilgrims traveling through one of the travel company and are attending the Hajj orientation courses were consecutively enrolled and assigned to receive health education via smartphone application as the intervention group. The health education intervention module on knowledge, attitude, and practice regarding RTIs prevention among Hajj pilgrims were developed as a smartphone application through a process of consultations with a panel of experts consisting of epidemiologist, microbiologist, health educationist, computer scientist, and medical statistician. The module was developed based on the health belief model (HBM). The HBM alluded the high predictive capacity if an individual will adopt practices to prevent diseases, if they see themselves as susceptible to the disease (perceived susceptibility), if they consider it would produce conceivably severe health outcomes (perceived severity), if they consider that a singular practice accessible to them would decrease the susceptibility or severity or lead to other positive outcomes (perceived benefits), and if they perceive few negative characteristics linked to the health action (perceived barriers) (26). The percentage of variance explained by the HBM should be enough to produce a significant effect. In addition, the educational module was tested among 10 pilgrims who did not participate in the study for clarity of meaning, language and the flow of contents. The module consisted of five main activities applied from the HBM (27). We used various behavioral change techniques to enhance the pilgrims' motivation to make lifestyle changes during Hajj. They were: first, "Perceived susceptibility of pilgrims toward RTIs"; pilgrims were educated on their perceptions toward the cause and risk of RTIs during Hajj. Second, "Perceived severity of RTIs" referred to the beliefs a person holds concerning the complications of RTIs; this technique informed the pilgrims about these effects and educated them. Third, "Perceived benefit for the prevention of RTIs"; pilgrims were educated on health behavior to adopt to prevent RTIs. Fourth, "Perceived barriers for the prevention of RTIs"; pilgrims were taught of the disadvantages or potential obstacles they must to overcome in attempting to improve their behaviors. Lastly, "cues to action for RTI prevention of RTIs"; we used an interactive, user-friendly smartphone application to stimulate awareness and change behavior.

The Health education intervention application (Hajj HEM) has several major components, including (1) pages for registering the users and collecting the individual's personal health data, which is the information users want to protect in the app; (2) pages demonstrating the overview of respiratory tract infection and prevention steps for contracting the infections. First of all, the user registers an account and key in some personal health information. Users can go to the application based on the menu options. Users can also go to the formative assessment section and use the interactive questions and answers to assess their understanding of the health education module. To overcome the challenges of lost in internet connection, the application was designed to function even without an internet connection once it is installed in the smartphone. The final version of the Hajj HEM application can be assessed through this URL https://play.google.com/store/apps/details?id=my.usm. hc.sms.hajjhem. The application was restricted to only pilgrims that consented to participate in the study.

Participants were encouraged to be compliant regarding the usage of the smartphone application before, during and after Hajj. The formative assessment section was included in the module for the evaluations of participants comprehension, learning needs and progress throughout the intervention. Formative assessments also help the researcher identify concepts that participants are struggling to understand, how participants comply with the application. Similarly, sections were provided regarding "Feedback from users about the content" and "Feedback from users about the app."

\section{Measurement of Outcome Variables}

The outcome variables for this study was the change in knowledge, attitude, and practice regarding RTI prevention. Knowledge had 29 questions and had "Yes" or "No" options. Correct answers attracted one mark while wrong answers were scored zero. A respondent could get scores within the range of 0-29 scores. Attitude had 12 questions measured on a fivepoint Likert scale with strongly disagree $=1$, Disagree $=$ 2 , Not sure $=3$, Agree $=4$, and strongly agree $=5$. The scores ranged from 12 to 60 . Practices had 13 questions with 
"Always," “Occasional," and "Never" options. Each item was given score 2 for "always" response, 1 for "occasional" and 0 for "never" responses. A total possible maximum score on the practice domain was 26 and the minimum was 0 . Higher scores imply a higher positive knowledge, attitude, and practice toward RTI prevention, while poor scores show mistrust of preventive strategies and/or negative views toward the need for preventive practices.

\section{Data Analysis}

Data entry and analysis was performed using Statistical package for social sciences (SPSS) version 22 (IBM, 2014). Frequencies, percentage, mean (standard deviation) were analyzed using descriptive statistics. Chi-square test and Fisher exact test was used to analyse the association of categorical variables between intervention and control groups. However, independent sample $t$-test assuming equal variance was used to compare between the intervention and control groups. $P<0.05$ were considered to be statistically significant. For the evaluation of the effectiveness of the health education intervention, mixed-design ANOVA was primarily the analytical method employed to understand if there is an interaction within-subjects effect, between-subjects effect and time (28). Partial eta squared ( $\eta 2$ ) was the measures of effect size. The strength of partial eta square ( $\eta 2)$ was interpreted as small effect $=0.01$, moderate effect $=0.06$, larger effect $=$ 0.14 (29).

\section{Ethical Issues}

Ethical clearance to conduct the study was obtained from Universiti Sains Malaysia, Ethics Committee for Research Involving Human Subjects (ref no: USM/JEPeM/17020146). and Universiti Sultan Zainal Abidin Malaysia human research ethics committees (UniSZA/UHREC/2019/88). Informed written consent was obtained from each participant. In addition, the trial was registered with Australian New Zealand Clinical Trials Registry (ANZCTR) with registration number ACTRN12619000217101.

\section{RESULTS}

A total of one hundred and thirty-two (132) Hajj pilgrims were recruited for this study from 2 purposely selected private Hajj and Umrah tour companies during the pre-intervention study. These participants were grouped into intervention (65) and control (65) groups. However, during the post-intervention, 13 respondents from the intervention group and 15 respondents from control group were lost to follow up giving a response rate of 83.87 and $76.92 \%$, respectively One of the Hajj tour company was allocated the control group, and the other tour company was allocated the intervention group to reduce contamination at baseline assessment, as shown in Figure 1.

\section{Socio-Demographic Characteristics by Groups}

Table 1 displays the socio-demographic characteristics and the presence of RTIs symptoms of the Hajj pilgrims in the intervention and control groups at baseline. The results showed that there was no significant difference between the two groups.
The control and the intervention groups were comparable at baseline. The KAP questionnaire was re-administered at three to 4 weeks after intervention upon return from Hajj. However, data was collected from $52(80 \%)$ and 50 (76.9\%) at post-intervention from both intervention and control arms, respectively. The age of the respondents during the intervention study ranged from 20 to 73 years, with a mean (SD) age of 46.90 (12.78) years. Majority of the respondents are females in both groups. Most of the respondents (76.5\%) were married, while half of them $(50.0 \%)$ are civil servants. In terms of the level of education, bachelor's degree, and secondary holders are the majority, and they account for $36.3 \%$ each.

\section{Effectiveness of Intervention on KAP Mean Score Based on Time}

For the effectiveness of the health education intervention based on time effect, a significant difference of mean knowledge score in the intervention group based on time $(F=0.31, p=0.002)$ was revealed in the analysis. Therefore, multiple paired $t$ tests were done with adjusted $\alpha$ based on Bonferroni correction, as shown in Table 2. Results of the paired $t$ test showed that there was a significant difference in the pre-post-test intervention (mean difference $=3.46$, 95\% CI: $1.29,5.63 ; p=0.002$ ) for the intervention group. However, results for the control group, based on the paired $t$ tests showed that there was no significant difference in the pre-post intervention (mean difference $=0.46$, $95 \% \mathrm{CI}:-1.22,2.14 ; p=0.584)$. In conclusion, with regards to the knowledge domain, there was a significant difference in mean knowledge score within the intervention group only based on time while the control group showed no significant difference.

In the attitude section, there was also a significant difference in mean attitude score within the intervention group based on time $(F=4.677, p<0.001)$. Similarly, multiple paired $t$ tests were conducted as shown in Table 2 and which indicated a significant statistical difference in pre-posttest (mean difference $=2.173$, 95\% CI: $0.156,4.190 ; p=0.035$ ) for the intervention group only. On the other hand, for the control group, there was no significant statistical difference in the pre-post intervention. In conclusion, for attitude, there was a significant difference in the mean attitude score within the intervention group only based on time.

Whereas, for the practice section, there was also a significant difference in mean practice score within the intervention group only based on time $(F=20.989, p<0.001)$. Multiple paired $t$ tests were performed (Table 2) and showed that there was a significant difference in the pre-posttest (mean difference $=2.73,95 \% \mathrm{CI}$ : $1.53,3.93 ; p<0.001$ ) of the intervention group. While for the control group, paired $t$ tests showed that there were no significant differences in the pre-post (mean difference $=0.96 ; 95 \% \mathrm{CI}$ : $-0.29,2.21 ; p=0.129)$. In conclusion, there was a significant difference in the mean practice score within the intervention group only based on time.

\section{Effectiveness of Intervention on KAP Mean Scores Based on Group Regardless of Time}

From Tests of Between-Subjects Effects, the findings of this study indicated there were no any significant differences of mean 


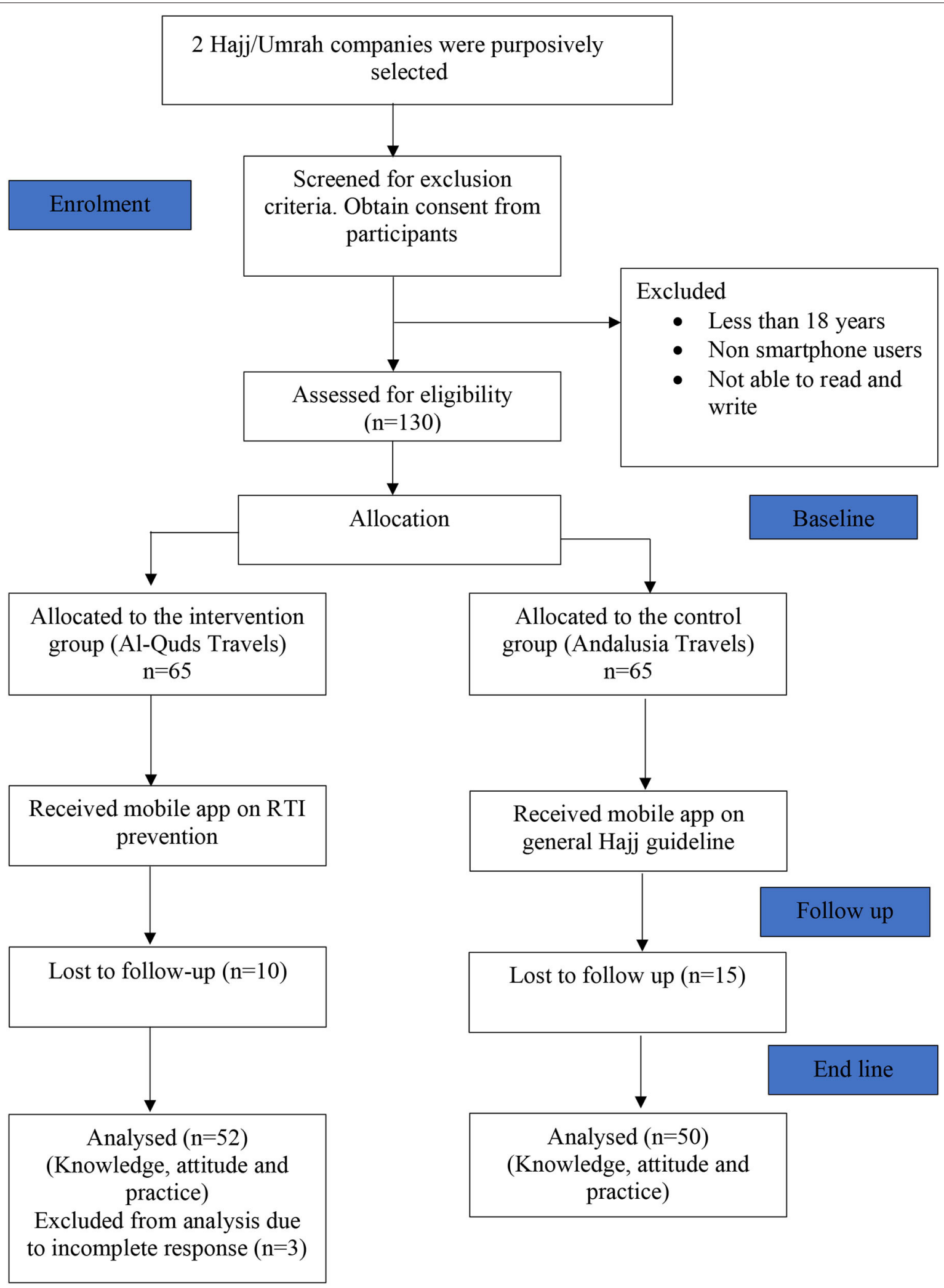

FIGURE 1 | Flow chart of respondents in a quasi-experimental study conducted among Haij pilgrims in private Hajj companies from Kelantan, Malaysia. 
TABLE 1 | Socio-demographic characteristics of the respondents.

\begin{tabular}{|c|c|c|c|}
\hline Socio-demographic factor & $\begin{array}{c}\text { Intervention } n=52 \\
n(\%)\end{array}$ & $\begin{array}{c}\text { Control } n=50 \\
n(\%)\end{array}$ & $p$ \\
\hline
\end{tabular}

\begin{tabular}{|c|c|c|c|}
\hline \multicolumn{4}{|l|}{ Age (years) } \\
\hline Mean (SD) & $48.88(11.75)$ & $44.84(13.57)$ & $0.110^{\mathrm{a}}$ \\
\hline \multicolumn{4}{|l|}{ Gender } \\
\hline Male & $16(30.8)$ & $14(28.0)$ & \multirow[t]{2}{*}{$0.465^{b}$} \\
\hline Female & $36(69.2)$ & $36(72.0)$ & \\
\hline \multicolumn{4}{|l|}{ Marital status } \\
\hline Married & $46(82.7)$ & $35(70.0)$ & \multirow[t]{3}{*}{$0.083^{c}$} \\
\hline Single & $6(11.5)$ & $14(28.0)$ & \\
\hline Divorced/widowed & $3(5.8)$ & $1(2.0)$ & \\
\hline \multicolumn{4}{|l|}{ Occupation } \\
\hline Civil servant & $24(46.2)$ & $27(54.0)$ & \multirow[t]{6}{*}{$0.692^{c}$} \\
\hline Self employed & $5(9.6)$ & $4(8.0)$ & \\
\hline Private & $5(9.6)$ & $5(10.0)$ & \\
\hline Pensioner & $13(25.0)$ & $7(14.0)$ & \\
\hline Housewife & $4(7.7)$ & $4(8.0)$ & \\
\hline Student & $1(1.9)$ & $3(6.0)$ & \\
\hline \multicolumn{4}{|c|}{ Highest level of education } \\
\hline Ph.D. & $4(7.7)$ & $0(0)$ & \\
\hline Master's degree & $3(5.8)$ & $4(8.0)$ & \\
\hline Bachelor's degree & $16(30.8)$ & $21(42.0)$ & \\
\hline Diploma & $11(21.2)$ & $6(12.0)$ & \\
\hline Secondary school & $18(34.6)$ & $19(38.0)$ & \\
\hline \multicolumn{4}{|c|}{ Previous Hajj experience } \\
\hline Yes & $16(30.8)$ & $9(18.0)$ & \multirow[t]{2}{*}{$0.102^{b}$} \\
\hline No & $36(69.2)$ & $41(82.0)$ & \\
\hline \multicolumn{4}{|c|}{ Previous Umrah experience } \\
\hline Yes & $16(30.8)$ & $11(22.0)$ & \\
\hline No & $36(69.2)$ & $39(78.0)$ & \\
\hline \multicolumn{4}{|c|}{ Influenza vaccination history } \\
\hline Yes & $15(28.8)$ & $13(26.0)$ & \multirow[t]{2}{*}{$0.460^{b}$} \\
\hline No & $37(71.2)$ & $37(74.0)$ & \\
\hline \multicolumn{4}{|c|}{ Pneumococcal vaccination history } \\
\hline Yes & $12(23.1)$ & $13(26.0)$ & \multirow[t]{2}{*}{$0.455^{b}$} \\
\hline No & $40(76.9)$ & $37(74.0)$ & \\
\hline \multicolumn{4}{|c|}{ Presence of influenza-like illnesses symptoms before departure } \\
\hline Yes & $2(3.8)$ & $1(2.0)$ & \multirow[t]{2}{*}{$1.000^{\mathrm{a}}$} \\
\hline No & $50(96.2)$ & $49(98.0)$ & \\
\hline \multicolumn{4}{|c|}{ Presence of common cold symptoms before departure } \\
\hline Yes & $2(3.8)$ & $1(2.0)$ & \multirow[t]{2}{*}{$1.000^{\mathrm{a}}$} \\
\hline No & $50(96.2)$ & $49(98.0)$ & \\
\hline
\end{tabular}

${ }^{a}$ t-test.

${ }^{b}$ Fisher's exact test.

${ }^{c}$ Pearson Chi-square.

knowledge, attitude, and practice scores between intervention and control groups $(p=0.169, p=0.101$, and $p=0.078$, respectively) regardless of time. The mean knowledge, attitude and practice scores were higher in the intervention group compared to the control group (Table 3). However, the results also showed the main effect for the between-group factor analyses (partial $\eta 2$ ) based on knowledge, attitude and practices scores as
TABLE 2 | Comparison of KAP scores of RTI prevention during Hajj/Umrah within each group based on time (time effect).

\begin{tabular}{|c|c|c|c|c|}
\hline \multirow[t]{2}{*}{ Comparison } & \multicolumn{2}{|c|}{ Intervention group ( $n=66$ ) } & \multicolumn{2}{|c|}{ Control group $(n=66)$} \\
\hline & Mean Diff $(95 \% \mathrm{Cl})$ & $p$ & MD (95\% Cl) & $p$ \\
\hline \multicolumn{5}{|l|}{ Knowledge } \\
\hline Pre-post intervention & $3.46(1.29,5.63)$ & 0.002 & $0.46(-1.22,2.14)$ & 0.584 \\
\hline \multicolumn{5}{|l|}{ Attitude } \\
\hline Pre-post intervention & $2.17(0.16,4.19)$ & 0.035 & $0.52(-0.99,2.03)$ & 0.492 \\
\hline \multicolumn{5}{|l|}{ Practice } \\
\hline Pre-post intervention & $2.73(1.53,3.93)$ & $<0.001$ & $0.96(-0.29,2.21)$ & 0.129 \\
\hline
\end{tabular}

Repeated measures ANOVA within-group analysis was applied followed by pairwise comparison with $95 \%$ confidence interval adjustment by Bonferroni correction. MD, mean difference.

TABLE 3 | Comparison of KAP scores of RTI prevention among Hajj/Umrah pilgrims between groups (Group effect regardless of time).

\begin{tabular}{|c|c|c|c|c|}
\hline Comparison & Mean $(95 \% \mathrm{Cl})$ & F-stat (df) & $p$ & $\begin{array}{c}\text { Partial Eta } \\
\text { Squared }\end{array}$ \\
\hline \multicolumn{5}{|l|}{ Knowledge } \\
\hline Control & $16.15(14.81,17.49)$ & $1.92(1)$ & 0.169 & 0.019 \\
\hline Intervention & $17.46(16.15,18.78)$ & & & \\
\hline \multicolumn{5}{|l|}{ Attitude } \\
\hline Control & $31.96(30.77,33.16)$ & $2.74(1)$ & 0.101 & 0.027 \\
\hline Intervention & $33.36(32.18,34.53)$ & & & \\
\hline \multicolumn{5}{|l|}{ Practice } \\
\hline Control & $26.58(25.38,27.78)$ & $3.18(1)$ & 0.078 & 0.031 \\
\hline Intervention & $28.10(26.92,29.28)$ & & & \\
\hline
\end{tabular}

Repeated measures ANOVA between-group analyses were applied Level of significance was set at 0.05 (two-tailed).

$0.019,0.027$, and 0.031 respectively based on the cut-off points for 0.01 (small), 0.09 (medium), and 0.25 (large) (30).

\section{Effectiveness of Intervention on Mean KAP Scores Based on Time-Group Interaction (Group Effect With Regard to Time)}

Based on the findings of the interaction of time and group, there was a significant statistical difference for post intervention based on estimated marginal means for knowledge $(p=0.005)$, attitude $(p=0.041)$, and practice $(p=0.002)$ as shown in Table 4. However, for pre intervention, the estimated marginal means for knowledge, attitude, and practice showed a non-significant result.

\section{DISCUSSION}

This study employed an interactive, self-operated, and novel smartphone health education module application to improve knowledge, attitude, and practice toward RTI prevention during Hajj among the participating pilgrims in the intervention group. The smartphone application was considered as the format of the intervention as the literature review provided several studies of successful digital-based interventions for health $(31,32)$. 
TABLE 4 | Comparison of KAP score for RTI prevention among the intervention and control group based on time (Time-treatment interaction).

\begin{tabular}{llccc}
\hline & Comparison & Mean score & 95\% Cl & $\boldsymbol{P}$ \\
\hline Knowledge & & & & \\
Pre-intervention & Control & 15.90 & $14.08,17.77$ & 0.885 \\
& Intervention & 15.73 & $13.92,17.54$ & \\
Post-intervention & Control & 16.38 & $14.94,17.82$ & $\mathbf{0 . 0 0 5}$ \\
& Intervention & 19.192 & $17.78,20.61$ & \\
Attitude & & & & \\
Pre-intervention & Control & 31.70 & $30.24,33.16$ & 0.583 \\
& Intervention & 32.27 & $30.84,33.70$ & \\
Post-intervention & Control & 32.22 & $30.70,33.74$ & $\mathbf{0 . 0 4 1}$ \\
& Intervention & 34.44 & $32.95,35.93$ & \\
Practice & & & & \\
Pre-intervention & Control & 26.10 & $24.53,27.67$ & 0.571 \\
& Intervention & 26.731 & $25.19,28.27$ & \\
Post-intervention & Control & 27.06 & $25.98,28.27$ & $\mathbf{0 . 0 0 2}$ \\
& Intervention & 29.46 & $28.40,30.52$ & \\
\hline & & & & \\
\hline
\end{tabular}

Repeated measures ANOVA between group analysis with regard to time was applied followed by pairwise comparison with $95 \%$ confidence interval adjustment by Bonferroni correction. Assumption of normality, homogeneity of variances, and compound symmetry were checked and were fulfilled.

Striking instances include a digital health intervention, which has been reported to promote adherence to medical therapies and knowledge and understanding of cancer (33), and a smartphone application to enhance health knowledge, attitude, practice, and safety among University Students in Malaysia (34). The extensive choice of mobile phones highlights a vital chance to reshape health behaviors worldwide, especially in low- and middleincome nations (12). Conducting a study using a mobile phone technology to gather information on infections associated with mass gathering and travelers makes compliance with prevention practices achievable. It can also render useful data connected to health-related behavior (35).

The intervention program based on the generalizable modified HBM tested in this study showed significant benefits in terms of RTI prevention and increased health knowledge and health behavior. Furthermore, for participants who complied well with the health education module, the outcomes were significantly higher in the intervention group compared with the control subjects from baseline to post-intervention. These findings are also supported by a study conducted by Medley et al. (36). The intervention program based on the modified HBM employed in this study demonstrated remarkable achievement in terms of RTI prevention and advancement of health knowledge and health behavior. However, for pilgrims that participated and complied with the intervention module, the study outcomes were higher in the intervention arm when compared with the control arm from pre-intervention to the post-intervention. These results are also backed by findings from several studies $(30,37,38)$.

There was an increase in the total knowledge scores for both intervention and control groups, which could be due to the general regular lectures and courses that are not guided by any health behavior theory given to pilgrims attending private Hajj company's regular orientation. Also, the billboards, signages, and posters displayed in Makkah and other Hajj areas. Similarly, Saudi authorities have made strict requirements and recommendations for visitors for Hajj to be in optimum health condition and physically fit (39). However, the mean KAP scores of the intervention were higher when compared with those of the control group. Consequently, the health education module is efficient in the advancement of knowledge, attitude, and practice related to RTI prevention among the respondents. The findings of our study are consistent with the finding of Alexandrino, Santos (40) which concluded that intervention has a positive effect on changing RTI infection knowledge in community settings. However, the present study indicates that the health education intervention and its compliance during Hajj led to improved knowledge, an attitudinal change regarding prevention and improved preventive practices as was seen in some studies (4143).

This study employed Mixed design ANOVA which permit the estimation of the interaction of group effects, time effects as well as random and fixed effects related to repeated measure in the study. The importance of this research as an organized health education intervention program via smartphone application on change in lifestyle that is focused and particular for Hajj pilgrims concerning RTIs is that it can be recognized for adoption in Malaysia and even beyond. To a certain degree in this study, the group $\mathrm{x}$ time interaction effect of our treatment on the knowledge, attitude, and practice outcomes improved statistically significant by the intervention. Therefore, the detected difference in the outcomes can potentially be due to the intervention provided. These findings are similar to the findings of a study conducted among respondents of the general Hajj population which showed a significant increase in knowledge toward healthy behaviors among pilgrims using health educators (43). This smartphone application had a small effect on the enhancing the attitude of respondents regarding RTIs prevention. Efforts at enhancing attitude regarding RTIs will ultimately produce an assertive influence on RTIs prevention among Hajj pilgrims. Regarding the prevention practices, our smartphone application, the effect size was within partial eta square cut-off score for a moderate effect.

To the best of our knowledge, this is the first study to evaluate the effect of a smartphone application for health education intervention in improving knowledge, attitude, and practice regarding RTIs among Hajj pilgrims in Malaysia. This study suggests a strong biologically plausible and significant relationship between our intervention and study outcomes. The beneficial effect of intervention reported in this study has substantial implications for attaining the control and prevention of RTIs during mass gatherings. The data analysis employed in this study ensured the estimation of the combination of fixed effects, random effects, and repeated measure in the analysis. Several steps were ensured to reduce bias and contamination despite the lack of randomization and blinding. It had been hypothesized that the practice 
of RTI prevention by Hajj pilgrim operates through the HBM, and an intervention guided by this model would positively affect these constructs, leading to improvements in preventive practices.

However, pilgrims that participated in this study were all from Malay ethnic group from one state that is predominantly a Muslim state in Malaysia, as such they may not be fully representative of pilgrims from Malaysia. The interpretation of the results from this research should be accomplished with prudence due to intrinsic deficiencies and hindrances in regarding its implementation. These points raised could limit the generalizability of our conclusions to the pilgrims from Malaysia, despite the use of purposive sampling. The importance of this research as a structured health education intervention program on change in lifestyle that is focused and particular for Hajj pilgrims regarding RTIs is that it can be recognized for adoption in Malaysia and even beyond. Further studies are needed in other parts of Peninsular Malaysia, as well as in Eastern Malaysia.

\section{CONCLUSION}

The health education module used in this study is considered as unique as it combines a panel of experts from a diverse group of specialists. Furthermore, the concept of its delivery and intervention is particularly unique by utilizing a new mobile phone application approach. Trained and skilled research assistants were recruited to deliver the module and ease of communication in Bahasa Malaysia spoken by most the targeted participants. The total knowledge, attitude, and practice scores were significantly high for the participants in the intervention arm when compared to those in the control arm. A such it can be inferred that the intervention was efficient in enhancing the outcomes of the study, though some improvement is still needed. The module developed is recommended to be included as a strategy and sensitization of participants during a mass gathering against RTIs.

\section{REFERENCES}

1. Saeed KMI, Mofleh J, Rasooly MH, Aman MI. Occurrence of acute respiratory infection, diarrhea and jaundice among Afghan pilgrims, 2010. J Epidemiol Glob Health. (2012) 2:215-20. doi: 10.1016/j.jegh.2012.11.003

2. Azeem MI, Tashani M, Badahdah AM, Heron L, Pedersen K, Jeoffreys N, et al. Surveillance of Australian Hajj pilgrims for carriage of potentially pathogenic bacteria: data from two pilot studies. World J Clin Cases. (2017) 5:102-11. doi: 10.12998/wjcc.v5.i3.102

3. Edouard S, Al-Tawfiq JA, Memish ZA, Yezli S, Gautret P. Impact of the hajj on pneumococcal carriage and the effect of various pneumococcal vaccines. Vaccine. (2018) 36:7415-22. doi: 10.1016/j.vaccine.2018.09.017

4. Hoang VT, Sow D, Belhouchat K, Dao TL, Ly TDA, Fenollar F, et al. Environmental investigation of respiratory pathogens during the Hajj 2016 and 2018. Travel Med Infect Dis. (2020) 33:101500. doi: 10.1016/j.tmaid.2019.101500

5. AboEl-Magd GH, Alkhotani N, Elsawy A. The prevalence and pattern of pneumonia among Hajj pilgrims: a study of two successive Hajj seasons. Egypt J Chest Dis Tuberc. (2020). 69:407. doi: 10.1016/j.chest.2020.05.058

\section{DATA AVAILABILITY STATEMENT}

The raw data supporting the conclusions of this article will be made available by the authors, without undue reservation.

\section{ETHICS STATEMENT}

The studies involving human participants were reviewed and approved by Universiti Sains Malaysia, Ethics Committee for Research Involving Human Subjects (Ref no: USM/JEPeM/17020146). Universiti Sultan Zainal Abidin Malaysia human research ethics committees (UniSZA/UHREC/2019/88). The trial was registered with Australian New Zealand Clinical Trials Registry (ANZCTR) with registration number ACTRN12619000217101. The patients/participants provided their written informed consent to participate in this study.

\section{AUTHOR CONTRIBUTIONS}

MG, HH, and ZD conducted the survey and drafted the initial manuscript. $\mathrm{NN}, \mathrm{HH}, \mathrm{NW}-\mathrm{A}, \mathrm{MA}$, and WA designed and supervised the study. $\mathrm{AB}$ and $\mathrm{BA}$ helped in the manuscript revision. All authors have read and approved the final manuscript.

\section{FUNDING}

School of Medical Sciences, Universiti Sains Malaysia Bridging Grant (304/PPSP/6316136) and Universiti Sultan Zainal Abidin (UniSZA) Malaysia which provided the Special Research Grant Scheme (UniSZA/2017/SRGS/16) to fund the research and USM Global Fellowship awarded to the first author.

\section{ACKNOWLEDGMENTS}

We would like to acknowledge the management and staff of Andalusia Hajj and Umrah Travels.

6. Johns Hopkins University. Coronavirus 2019-nCoV Global Cases by Johns Hopkins Coronavirus Resource Center (2020). Available online at: https:// coronavirus.jhu.edu/map.html (accessed at: 23 May, 2021)

7. Deris ZZ, Hasan H, Sulaiman SA, Wahab MSA, Naing NN, Othman $\mathrm{NH}$. The prevalence of acute respiratory symptoms and role of protective measures among Malaysian hajj pilgrims. J Travel Med. (2010) 17:828. doi: 10.1111/j.1708-8305.2009.00384.x

8. Hashim S, Ayub ZN, Mohamed Z, Hasan H, Harun A, Ismail N, et al. The prevalence and preventive measures of the respiratory illness among Malaysian pilgrims in 2013 hajj season. J Travel Med. (2016) 23:17. doi: $10.1093 / \mathrm{jtm} / \operatorname{tav} 019$

9. Zuraina NMN, Sarimah A, Suharni M, Hasan H, Suraiya S. High frequency of Haemophilus influenzae associated with respiratory tract infections among Malaysian Hajj pilgrims. J Infect Public Health. (2018) 11:87883. doi: 10.1016/j.jiph.2018.07.010

10. Pye J. Reducing the risk of respiratory disease in overseas travellers. Nurs Stand. (2010) 24:50-6; quiz 58. doi: 10.7748/ns.24.47.50.s54

11. Lupton D. Digitised health, medicine and risk. Health Risk Soc. (2016) 17:4736. doi: 10.1080/13698575.2015.1143247 
12. Zhao J, Freeman B, Li M. Can mobile phone apps influence people's health behavior change? an evidence review. J Med Internet Res. (2016) 18:e287. doi: 10.2196/jmir.5692

13. Bort-Roig J, Gilson ND, Puig-Ribera A, Contreras RS, Trost SG. Measuring and influencing physical activity with smartphone technology: a systematic review. Sports Med. (2014) 44:671-86. doi: 10.1007/s40279-014-0142-5

14. Kirwan M, Duncan M, Vandelanotte C. Smartphone apps for physical activity: a systematic review. J Sports Sci Med. (2013) 16:e47. doi: 10.1016/j.jsams.2013.10.113

15. Stephens J, Allen J. Mobile phone interventions to increase physical activity and reduce weight: a systematic review. J Cardiovasc Nurs. (2013) 28:3209. doi: 10.1097/JCN.0b013e318250a3e7

16. Alqahtani AS, BinDhim NF, Tashani M, Willaby HW, Wiley KE, Heywood $\mathrm{AE}$, et al. Pilot use of a novel smartphone application to track traveller health behaviour and collect infectious disease data during a mass gathering: Hajj pilgrimage 2014. J Epidemiol Glob Health. (2016) 6:14755. doi: 10.1016/j.jegh.2015.07.005

17. Alotaibi B, Yassin Y, Mushi A, Maashi F, Thomas A, Mohamed $\mathrm{G}$, et al. Tuberculosis knowledge, attitude and practice among healthcare workers during the 2016. Hajj. PLoS ONE. (2019) 14:e0210913. doi: 10.1371/journal.pone.0210913

18. Ghabrah TM, Madani TA, Albarrak AM, Alhazmi MA, Alazraqi TA, Alhudaithi MA, et al. Assessment of infection control knowledge, attitude and practice among healthcare workers during the Hajj period of the Islamic year 1423 (2003). Scand J Infect Dis. (2007) 39:101824. doi: 10.1080/00365540701466173

19. Tabatabaei A, Mortazavi SM, Shamspour N, Shushtarizadeh N. Health knowledge, attitude and practice among Iranian pilgrims. Iran. Red. Crescent Med J. (2015) 17:e12863. doi: 10.5812/ircmj.12863

20. Alkot M, Albouq MA, Shakuri MA, Subahi MS. Knowledge, attitude, and practice toward MERS-CoV among primary health-care workers in Makkah Al-Mukarramah: an intervention study. Int J Med Sci Public Health. (2016) 5:952-9. doi: 10.5455/ijmsph.2016.24012016345

21. Mohamed HH, Arshad MRHM, Rashid NA, Zainol Z, Husain W, Majid OA, et al. (editors). M-Umrah: an Android-based application to help pilgrims in performing Umrah. International Conference on Advanced Computer Science Applications and Technologies. IEEE (2013). doi: 10.1109/ACSAT.2013.82

22. Lemeshow S, Hosmer DW, Klar J, Lwanga SK, World Health Organization. Adequacy of Sample Size in Health Studies. Chichester: Wiley (1990).

23. Schulz KF, Altman DG, Moher D. CONSORT 2010 Statement: Updated guidelines for reporting parallel group randomised trials. J Clin Epidemiol. (2010) 63:834-40. doi: 10.1016/j.jclinepi.2010.02.005

24. Arifin WN. Sample size calculator (web). Unit of Biostatistics and Research Methodology. Universiti Sains Malaysia (2021). Retrieved from http:// wnarifin.github.io (accessed on May 23, 2021).

25. Goni MD, Naing NN, Hasan H, Wan-Arfah N, Deris ZZ, Arifin $\mathrm{WN}$, et al. Development and validation of knowledge, attitude and practice questionnaire for prevention of respiratory tract infections among Malaysian Hajj pilgrims. BMC Public Health. (2020) 20:1-10. doi: 10.1186/s12889-020-8269-9

26. Jones CL, Jensen JD, Scherr CL, Brown NR, Christy K, Weaver J. The health belief model as an explanatory framework in communication research: exploring parallel, serial, and moderated mediation. Health Commun. (2015) 30:566-76. doi: 10.1080/10410236.2013.873363

27. Orji R, Vassileva J, Mandryk R. Towards an effective health interventions design: an extension of the health belief model. Online J Public Health Inform. (2012) 4:ojphi.v4i3.4321. doi: 10.5210/ojphi.v4i3.4321

28. Field A. Discovering Statistics Using IBM SPSS Statistics: sage (2013).

29. Lakens D. Calculating and reporting effect sizes to facilitate cumulative science: a practical primer for t-tests and ANOVAs. Front. Psychol. (2013) 4:863. doi: 10.3389/fpsyg.2013.00863

30. Bisallah CI, Rampal L, Lye MS, Sidik SM, Ibrahim N, Iliyasu Z, et al. Effectiveness of health education intervention in improving knowledge, attitude, and practices regarding Tuberculosis among HIV patients in General Hospital Minna, Nigeria-A randomized control trial. PLoS ONE. (2018) 13:e0192276. doi: 10.1371/journal.pone.0192276

31. Fitzgerald M, McClelland T. What makes a mobile app successful in supporting health behaviour change? Health Educ J. (2017) 76:37381. doi: 10.1177/0017896916681179

32. Schoeppe S, Alley S, Van Lippevelde W, Bray NA, Williams SL, Duncan MJ, et al. Efficacy of interventions that use apps to improve diet, physical activity and sedentary behaviour: a systematic review. Int J Behav Nutr Phys Act. (2016) 13:127. doi: 10.1186/s12966-016-0454-y

33. Devine KA, Viola AS, Coups EJ, Wu YP. Digital health interventions for adolescent and young adult cancer survivors. JCO Clin Cancer Inform. (2018) 2:1-15. doi: 10.1200/CCI.17.00138

34. Sharifah NSI, Josfirin UR, Umi RA, Mohd AAS. Mobile apps application to improve safety and health knowledge, attitude and practice among university students. Malaysian J Med Health Sci. (2018) 14(SP1):47-55.

35. Alqahtani AS, Wiley KE, Mushta SM, Yamazaki K, BinDhim NF, Heywood AE, et al. Association between Australian Hajj Pilgrims' awareness of MERS$\mathrm{CoV}$, and their compliance with preventive measures and exposure to camels. J Travel Med. (2016) 23:taw046. doi: 10.1093/jtm/taw046

36. Medley A, Kennedy C, O'Reilly K, Sweat M. Effectiveness of peer education interventions for HIV prevention in developing countries: a systematic review and meta-analysis. AIDS Educ Prev. (2009) 21:181206. doi: 10.1521/aeap.2009.21.3.181

37. Chawla SPS, Kaur S, Bharti A, Garg R, Kaur M, Soin D, et al. Impact of health education on knowledge, attitude, practices and glycemic control in type 2 diabetes mellitus. J Family Med Prim Care. (2019) 8:2618. doi: 10.4103/jfmpc.jfmpc_228_18

38. Naing NN, Zain MM, Hamzah WM, Mat HA, Abdullah N, Bakar A, et al. A study of effectiveness of health education program on knowledge, attitude and practice (KAP) of food handlers toward foodborne diseases and food safety. Int Medical J. (2007) 14:253-60.

39. Ministry of Health Saudi Arabia. Health Regulations (2018). Available from: https://www.moh.gov.sa/en/hajj/pages/healthregulations.aspx. (accessed on May 23, 2021).

40. Alexandrino AMFdS, Santos RIGVd, Melo MCDAd, Bastos JAM. Designing and evaluating a health education session on respiratory infections addressed to caregivers of children under three years of age attending day-care centres in Porto, Portugal: a community-based intervention. Eur J Gen Pract. (2017) 23:43-50. doi: 10.1080/13814788.2016.1240777

41. Aelami M, Khajehdalouee M, Yagoubian H, Jamahdar SA, Pittet D. Implementation of an educational intervention among Iranian hajj pilgrims for the prevention of influenza-like illness. Antimicrob Resist Infect Control. (2015) 4: 48. doi: 10.1186/2047-2994-4-S1-O48

42. Alamri F, Amer S, Alhraiwil N. Knowledge and Practice after Health Education Program among Hajj 1438 H (2017). Pilgrims in Saudi Arabia. J Epidemiol Health Care. (2018). 1:7.

43. Turkestani A, Balahmar M, Ibrahem A, Moqbel E, Memish Z. Using health educators to improve knowledge of healthy behaviour among Hajj 1432 (2011) pilgrims. East Mediterr Health J. (2013) 19:S9-12. doi: 10.26719/2013.19.Supp2.S9

Conflict of Interest: The authors declare that the research was conducted in the absence of any commercial or financial relationships that could be construed as a potential conflict of interest.

Copyright (C) 2021 Goni, Naing, Hasan, Wan-Arfah, Deris, Arifin, Baaba, Adam and Arshad. This is an open-access article distributed under the terms of the Creative Commons Attribution License (CC BY). The use, distribution or reproduction in other forums is permitted, provided the original author(s) and the copyright owner(s) are credited and that the original publication in this journal is cited, in accordance with accepted academic practice. No use, distribution or reproduction is permitted which does not comply with these terms. 